\title{
Avaliação de cenários de Diabetes Mellitus na atenção básica
}

\author{
Jennifer Bazilio, Jessica Aquino Pereira, Maura \\ Cristiane Silva Figueira, Eliete Maria Silva, \\ Juliany Lino G. Silva, Verónica Rita D. Coutinho
}

Introdução: Os processos formativos em enfermagem passaram por diversas mudanças, tornando necessário um olhar crítico em relação às metodologias e recursos empregados. Dessa forma, as faculdades de enfermagem utilizam métodos de ensino que estimulam os alunos a vivenciarem a realidade de um atendimento clínico em ambientes simulados. A Atenção Básica prioriza ações de forma integralizada realizada por equipes de saúde de forma interdisciplinar oferecendo um serviço mais próximo da população, com ênfase na prevenção de doenças crônicas, como o diabetes mellitus. O profissional de enfermagem deve estar preparado para possíveis crises de hipoglicemia que ocorram nas Unidades Básicas. A recriação destes cenários tende a auxiliar os alunos no desenvolvimento de competências, identificando previamente os sinais e sintomas de uma crise evitando a evolução dos casos e fornecendo assistência segura aos pacientes. Objetivos: Avaliar cenário de crise hipoglicêmica na Atenção Básica. Método: Estudo descritivo de abordagem quanti/qualitativa, realizado com 27 alunos do $1^{\circ}$ ao $4^{\circ}$ ano do curso de enfermagem da Escola Superior de Enfermagem de Coimbra. Para a análise qualitativa dos dados seguimos o método de análise de conteúdo. Resultados: na abordagem quantitativa obtemos nas avaliações que em relação à pertinência do cenário, $85 \%$ dos participantes o classificaram como excelente e $15 \%$ como bom. Na avaliação de interesse quanto a prática $81 \%$ dos alunos escolheram a alternativa excelente e $19 \%$ como muito bom. $\mathrm{Na}$ avaliação qualitativa, para os estudantes o cenário de hipoglicemia foi muito realístico, possibilitando sistematizarem os pensamentos frente a crise, criando ligação entre a teoria e a prática clínica. $\mathrm{O}$ grande diferencial foi a interatividade com pessoas reais possibilitando estabelecer as prioridades no atendimento ao cliente. Todos os alunos assinaram o termo de consentimento, seguindo as exigências de pesquisas com seres humanos de Helsínquia. Conclusão: a simulação clínica possibilita aos estudantes executar a prática em diferentes cenários através de espaços protegidos. Considerações Finais: A construção e a avaliação de cenários contribuem para que a simulação atinja seus objetivos de forma mais eficiente, possibilitando modificações e adaptações, respeitando a opinião dos alunos expostos a ele.

Descritores: Educação Permanente, Educação em Saúde, Simulação, SUS, Paciente Simulado. 